\title{
Reducing liver cancer risk beginning at birth: experiences of preventing chronic hepatitis B virus infection in China
}

\author{
Chunfeng $\mathbf{Q u}^{1,2}$, Zhongping Duan ${ }^{3}$, Kun Chen ${ }^{1}$, Huaibin Zou ${ }^{3}$ \\ ${ }^{I}$ Department of Immunology, National Cancer Center/Cancer Hospital, Chinese Academy of Medical Sciences and Peking Union Medical College, Beijing \\ 100021, China. \\ ${ }^{2}$ State Key Laboratory of Molecular Oncology, National Cancer Center/Cancer Hospital, Chinese Academy of Medical Sciences and Peking Union Medical \\ College, Beijing 100021, China. \\ ${ }^{3}$ Artificial Liver Center, Beijing YouAn Hospital, Capital Medical University, Beijing 100069, China.
}

Correspondence to: Dr. Chunfeng Qu, Department of Immunology, National Cancer Center/Cancer Hospital, Chinese Academy of Medical Sciences and Peking Union Medical College, Beijing 100021, China. E-mail: quchf@cicams.ac.cn; Dr. Zhongping Duan, Artificial Liver Center, Beijing YouAn Hospital, Capital Medical University, Beijing 100069, China. E-mail:duan2517@163.com

How to cite this article: Qu C, Duan Z, Chen K, Zou H. Reducing liver cancer risk beginning at birth: experiences of preventing chronic hepatitis B virus infection in China. Hepatoma Res 2017;3:228-40.

\section{Article history: \\ Received: 4 Sep 2017 \\ Accepted: 18 Oct 2017 \\ Published: 25 Oct 2017 \\ Key words: \\ Hepatocellular carcinoma, \\ prevention, \\ vaccination, \\ antiviral therapy, \\ adolescent vaccine boost}

\begin{abstract}
In China, the death numbers due to primary liver cancer every year account for more than half of this disease burden worldwide. Hepatocellular carcinoma (HCC) represents the major histological type of primary liver cancer. In the Chinese population, at least $85 \% \mathrm{HCC}$ cases are due to chronic infection with hepatitis B virus (HBV), most of which were acquired in the perinatal period or in early life. As of January 1992, HBV immunization of newborns was introduced to the national Expended Program of Immunization of China. Prior to this program, the Qidong County in China conducted an hepatitis B intervention study, which was a population-based, cluster randomized, controlled trial of HBV vaccination in neonates. The study demonstrated that among young adults $<30$ years old, neonatal HBV immunization decreased around $84 \%$ risk of HBV-related liver cancer, and $70 \%$ risk of mortality due to severe end-stage chronic liver diseases. More than $72 \%$ efficacy of neonatal vaccination against chronic HBV infection in adulthood was achieved; however, when catch-up HBV vaccination was given to children at age 10-14 years, the protection efficacy was only $21 \%$. No difference in mortality of HBV-related liver diseases was observed among the young adults $<30$ years who received and those who did not receive the catch-up HBV vaccination. These results highlight the crucial importance of HBV vaccination of neonates in reducing the liver cancer risk beginning at birth in highly HBV endemic regions. Due to large numbers of HBV-infected pregnant women with high viremia in China, clinical studies in which antiviral therapy with the nucleot(s)ide analogues was given to HBV-infected pregnant women have provided important evidence that such therapy can reduce the risk of mother-to-child HBV transmission. These clinical data based on cohort studies, randomized clinical trials, and clinical practices in the Chinese population provide important information on prevention of liver cancer, particularly HCC, by preventing chronic HBV infection starting from birth for other populations.
\end{abstract}

This is an open access article licensed under the terms of Creative Commons Attribution 4.0 International License (https://creativecommons.org/licenses/by/4.0/), which permits unrestricted use, distribution, and reproduction in any medium, as long as the original author is credited and the new creations are licensed under the identical terms.

For reprints contact: service@oaepublish.com

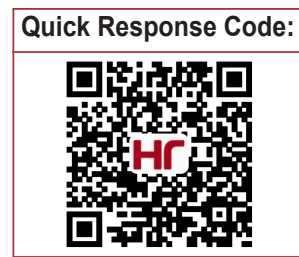




\section{INTRODUCTION}

Primary liver cancer (PLC) is one of leading causes of cancer deaths in China. Worldwide, hepatocellular carcinoma (HCC) represents the major histological type of liver cancer and likely accounts for $70-85 \%$ of cases, followed by intrahepatic cholangiocarcinoma (iCCA) which accounts for approximately $10-25 \%$ of all hepatobiliary malignancies ${ }^{[1]}$. Other risk factors for PLC include exposure to aflatoxin, algal hepatotoxins in drinking water, betel nut chewing, diabetes mellitus, alcohol consumption, and tobacco use ${ }^{[2]}$. Approximately $80 \%$ of $\mathrm{HCC}$ worldwide was estimated to be associated with chronic infections with hepatitis B virus (HBV) and hepatitis $\mathrm{C}$ virus $(\mathrm{HCV})^{[3]}$. Some studies also found the relationship between iCCA and HBV or $\mathrm{HCV}^{[4]}$, although their causal effects need to be further confirmed.

The contribution of HBV or HCV to HCC differs in different geographical areas, mainly due to the varied prevalence of HBV or HCV in different populations ${ }^{[1,3]}$. A meta-analysis including 39 studies in China from 1954 to 2010, based on the seroprevalence of hepatitis B surface antigen ( $\mathrm{HBsAg}$ ), and/or antibodies against $\mathrm{HCV}$ (anti-HCV) in HCC patients, reported that about $70 \%$ of HCC was associated with HBV infection alone, $5 \%$ with $\mathrm{HCV}$ infection alone, and $6 \%$ with HBV \& HCV co-infection. The analysis also suggested that around $19 \%$ of $\mathrm{HCC}$ was unrelated to HBV or $\mathrm{HCV}^{[3]}$.

HBV occult infection, which is indicated by undetectable serum HBsAg and low level of serum HBV DNA (sometimes HBV was detected only in the liver), has been frequently reported in different liver diseases ${ }^{[5,6]}$. In recent years, a substantial HBsAg-negative HCC patients were found to be serum HBV-DNA positive by using nucleic acid testing ${ }^{[7]}$. To understand the impact of HBV and/or HCV on PLC, Wang et al..$^{[8]}$ in National Cancer Center of China recently analyzed a total of 2,172 liver cancer cases, which were confirmed by histology. In this report, a total of 5,988 patients with PLC were identified from Northern regions of China (from January 1, 2003 to December 31, 2014) based on clinical diagnosis criteria. The analysis found no differences in the distributions of age, gender, ethnicity, and serological virus markers between the cases with and the cases without histological confirmation. Therefore, the proportion of HBV and/or HCV markers among the 2,172 histologically confirmed liver cancer cases could well represent the general cases ${ }^{[8]}$. Although the data were from one single medical center, the patients in this study were from diverse regions throughout all the provinces in the Northern regions of China. HBsAg seroprevalence was $4-6 \%$ in the Northern regions, lower than that of the overall population $(7.18 \%)$, while anti-HCV prevalence was $0.53 \%$, higher than that of the overall population
$(0.43 \%)^{[9,10]}$. The seroprevalence of HBV and/or HCV serological markers among the liver cancer patients from these regions is helpful to understand the impact of $\mathrm{HBV}$ and/or HCV on this disease in China.

The study by Wang et al. ${ }^{[8]}$ reported that $83.9 \%$ of liver cancer patients with histological confirmation were HCC and $11.0 \%$ were iCCA. Among the $1,823 \mathrm{HCC}$ patients, $1,567(86.0 \%)$ cases had HBV markers alone, indicated by $\mathrm{HBsAg}(-) /(+)$ \& anti-HBc(+). Remarkably, $18.2 \%$ of them were $\mathrm{HBsAg}(-)$ \& anti-HBc(+) and serum HBV-DNA positive. HCV infection alone, indicated by presence of anti-HCV(+), was found in $2.5 \%$ of HCC cases, and HBV \& HCV co-infection were found in $6.7 \%$ of $\mathrm{HCC}$ cases. Altogether, the contribution of HBV infection to $\mathrm{HCC}$ was at least $85-90 \%{ }^{[8]}$. This study indicated that the contribution of HBV infection to HCC in China had been under-estimated previously, most probably due to the unrecognized status of occult HBV infection among the HBsAg-negative HCC cases. The role of chronic HBV infection in HCC in China is clearly dominant. Therefore, controlling chronic HBV infection is crucial for reducing the risk of liver cancer, particularly HCC.

Although some perinatal infections from maternal HBV transmission may cause fulminant hepatitis in infancy ${ }^{[11]}$, a fatal disease of acute hepatocyte necrosis leading to hepatic encephalopathy and coagulopathy, HBV infection in infancy or early childhood leads to a high rate of persistent infection ${ }^{[12]}$. It was reported that among infected neonates born to mothers with positive hepatitis $\mathrm{B}$ e antigen ( $\mathrm{HBeAg})$, the chronicity of $\mathrm{HBV}$ infection was $80-90 \%{ }^{[12]}$. Of children infected before 6 years of age, chronic infection was reported to develop in approximately $30 \%{ }^{[13,14]}$. It had been documented that the majority of persons with chronic HBV infection in China acquired it at birth or in early childhood ${ }^{[15]}$.

Long-term major adverse outcomes of chronic HBV infection are liver cancer and cirrhosis. Longitudinal studies of untreated persons with chronic HBV infection showed that there is about $8-20 \%$ of cumulative risk of developing cirrhosis over five years. In those with cirrhosis, there is an approximately $20 \%$ annual risk of hepatic decompensation and the annual incidence of $\mathrm{HCC}$ could be as high as to $5 \%^{[16]}$. Therefore, it is important to reduce the risk of liver cancer beginning at birth or in early childhood by preventing chronic HBV infection.

\section{Brief history of HBV vaccination program and its effect in reducing HBsAg seroprevalence in China}

The relationship of chronic HBV infection and HCC development was well established based on a 
prospective study of 22,707 men in Taiwan ${ }^{[17]}$. In 1992, before the national HBV vaccination program was implemented, HBsAg seropositive rate in the 1-4 age group was $9.67 \%$, as high as in the general population $(9.75 \%)^{[15]}$, reflecting the fact that most of the chronic infections in Chinese population were acquired in the perinatal period or in early life. It is instrumental to reduce the incidences and mortalities of $\mathrm{HCC}$ and other liver diseases through universal HBV vaccination for infants and children. The Chinese government therefore developed a substantial number of policies to promote and implement the vaccination program ${ }^{[18,19]}$. A brief history of the HBV vaccination program is summarized in Figure 1.

The plasma-derived HBV vaccine was firstly manufactured and found to be effective in humans in clinical trials ${ }^{[20-22]}$. In 1982 two plasma-derived HBV vaccines, which were prepared from plasma of chronic HBsAg carriers, from France and from the United States were licensed ${ }^{[23]}$. A World Health Organization (WHO) Scientific Group meeting was convened from Jan 30 to Feb 4, 1983 to discuss HBV vaccination for the prevention of $\mathrm{PLC}{ }^{[24]}$. Millions of the first-generation plasma-derived vaccines were administered worldwide to neonates, infants, children, and adults at high-risk, and the effectiveness and safety records are excellent ${ }^{[18,23,25]}$. Due to the large population and high prevalence of HBV in China, the most important technical issue was to provide a safe and effective HBV vaccine sufficient to meet the requirement of immunizing 20 million newborns each year as well as other high risk groups. Through technical transfer from Merck, China manufactured both plasma-derived and recombinant $\mathrm{HB}$ vaccines domestically in late $1980 \mathrm{~s}^{[18]}$. With the maturation of recombinant DNA technology, the recombinant vaccines, prepared from yeasts, or from mammalian cells, were manufactured in early 1993 , and entirely replaced the plasma-derived vaccine in $1997^{[18,19,26]}$.
Beginning in January 1992 universal immunization to newborns was integrated into the national Expended Program of Immunization (EPI) of China with the family paying for all the costs ${ }^{[18,19]}$. Due to the relative high vaccine cost during that period, the immunization was mainly carried out in some urban areas and the wealthier Eastern provinces of China. From 1 January 2002, the vaccines were provided for free and the family paid only for user fee ${ }^{[18,19]}$. Between 2002-2007, with the support from the Global Alliance for Vaccines and Immunization and the central government of China, HBV vaccination was fully integrated into routine immunization to all infants in Western region and in poverty-affected counties in the Central regions of China, and from 2008 the central government of China took over the $\cos ^{\left[{ }^{[19]}\right.}$.

In 2006 (14 years after universal HBV immunization to newborns), the Chinese government conducted a national hepatitis serosurvey in the same areas as did in 1992 by measuring the prevalence of HBV markers among the population aged 1-59 years to evaluate the impact of the HBV vaccination program. Overall, 82,078 persons were surveyed, from whom 82,008 blood samples were collected. Among the general population aged 1-59 years, the prevalence of $\mathrm{HBsAg}$, anti-HBs, and anti-HBc were $7.2 \%, 50.1 \%, 34.1 \%$, respectively. However, the HBsAg prevalence was greatly reduced among those age $<15$ years compared to that found in the 1992 national serosurvey. The HBsAg seroprevalence in the $1-4$ age group was $0.96 \%{ }^{[27]}$, which was significantly reduced compared to the same group studied in $1992^{[15]}$. The HBsAg seroprevalence was also reduced in the $5-59$ age group, with a $2.32 \%$ seroprevalence in the 5-14 age group, and a 5.4\% seroprevalence in the 15-19 age group, and more than $8.0 \%$ in individuals aged 20 59 years $^{[27]}$. Further investigation was done in the same areas in 2014 among the 1-29 years age group. The HBsAg seroprevalence was $2.64 \%$ (95\% Cl: $2.28-3.06 \%)$ in 2014 and decreased by $73.92 \%$ as compared with the

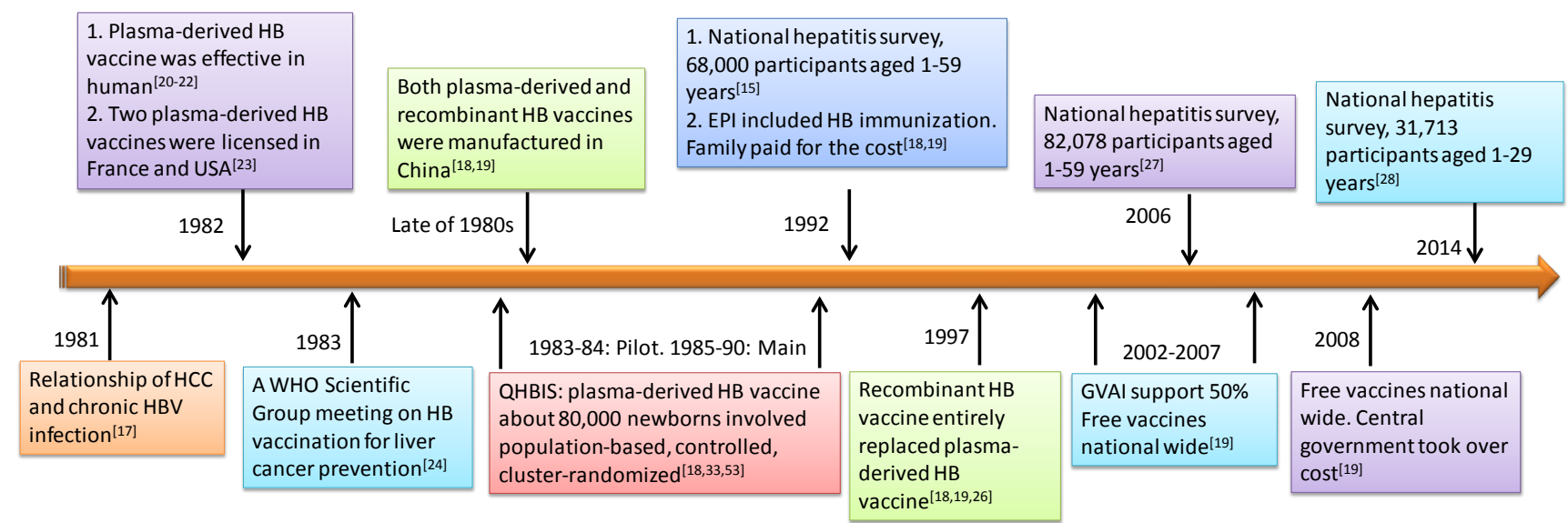

Figure 1: Brief history of HBV vaccination program in China. HBV: hepatitis B virus; HCC: hepatocellular carcinoma; WHO: World Health Organization; QHBIS: Qidong Hepatitis B Intervention Study; EPI: Expended Program of Immunization 
rate of $10.13 \%(95 \% \mathrm{Cl}: 9.81-10.45 \%)$ in 1992. Further analysis found that $\mathrm{HBsAg}$ prevalence was only $0.64 \%$ (95\% Cl: $0.54-0.75 \%)$ in 2014 among those (1-12 years of age) who were born between 2002-2013 after HBV vaccination was integrated into national EPI program ${ }^{[28]}$. China has already reached the national goal of reducing HBsAg prevalence to less than $1 \%$ among children under 5 years, and an estimated 16-20 million HBV carriers were prevented through the HBV vaccination program ${ }^{[27]}$.

\section{Reduced liver cancer incidence in general population by historical comparison cannot be entirely attributed to HBV vaccination}

Some perinatal infection from maternal HBV transmission may cause fulminant hepatitis in infancy ${ }^{[11]}$, a very rare condition that develops in about $0.5-1 \%$ of cases $^{[29]}$. Mortality rate of fulminant hepatitis can be as high as $67 \%^{[30]}$. Reports from several countries and areas have documented the dramatic decrease of the incidence of fulminant hepatitis after HBV immunization to newborns was implemented ${ }^{[31-34]}$. However, the infection in the perinatal period and early life mainly resulted in chronic HBV infection, which could be as high as $90 \%{ }^{[12,14]}$.

Long-term major adverse outcomes of chronic HBV infection are liver cancer and cirrhosis. Studies from Taiwan, which analyzed data based on cancer registry in birth cohorts born after the universal vaccination program as compared to the birth cohorts born before the program, documented that HBV vaccination was effective in reducing the incidence and mortality of liver cancer ${ }^{[35]}$. A study among the Alaskan Native of the United States reported the elimination of $\mathrm{HCC}$ and acute hepatitis B in children 25 years after a HBV immunization program ${ }^{[36]}$. Studies based on the cancer registry data of Korea ${ }^{[37]}$ and $\mathrm{Japan}^{[38]}$ also reported a decreased incidence of liver cancer after the implementation of HBV vaccination programs. In China, the time trend analysis of liver cancer incidence during 1988-2005 also showed a gradual decrease based on the cancer registry data in 11 cities and counties that covered a population of $401,506,812$ (male patients 204,475,147; female patients $197,031,665$, sex ratio 1.04). The annual percent change was $-1.44 \%{ }^{[39]}$. Recent analysis showed that the agestandardized liver cancer incidence rate during 20002011 was further decreased with an average annual percentage change of $-1.8 \%{ }^{[40]}$, reflecting the effect of $\mathrm{HBV}$ vaccination in reducing liver cancer risk.

Chronic HBV infection is the most important risk factor for liver cancer in humans, which is endemic in the regions of Africa and Asia, especially in China. The other established etiological factors also include heavy exposure to aflatoxin, algal hepatotoxins in contaminated water, betel nut chewing, diabetes mellitus, and alcohol abuse leading to liver cirrhosis ${ }^{[2]}$. In addition, cohort studies showed that the intakes of vitamin $\mathrm{C}^{[41]}$ and vitamin $E^{[42]}$, from both diet and supplements could potentially reduce the risk of liver cancer. Reducing the dietary aflatoxin exposure to non-detectable levels could also reduce $\mathrm{HCC}$ cases in high risk areas by about $23 \%{ }^{[43]}$. An observational study in a rural population indicated that decline of liver cancer incidence in the younger generation was not fully attributed to controlling chronic HBV infection alone. Changes in their staple food and drinking water were also important in reducing liver cancer risk $^{[44]}$. A study conducted in an urban area of China reported the positive roles of vegetablebased dietary pattern in decreasing liver cancer risk ${ }^{[45]}$. All studies based on cancer registry data historically comparing the immunized and unimmunized cohorts at either the national or community level, support the hypothesis that HB vaccination is associated with a reduced risk of liver cancer. Nevertheless, because of potential differences in baseline characteristics and in exposures to other risk factors ${ }^{[2]}$ between the immunized and historical comparison (unimmunized) birth cohorts, it is difficult to make the inference that the observed reduced liver cancer risk was entirely attributed to HBV vaccination $^{[35,44,46]}$. The Qidong Hepatitis B Intervention Study (QHBIS) addressed the causal link between HBV vaccination and the observed benefits ${ }^{[3,47,48]}$.

\section{Efficacies of HBV vaccination in preventing liver cancer and other liver diseases in rural China: experience from Qidong Hepatitis B Intervention Study}

Qidong County, China, is a rural area with high liver cancer incidence and mortality compared to China as a whole. The incidence of PLC in Qidong was 79.6/10 5 for man and $23.1 / 10^{5}$ for woman during $1978-2002^{[49]}$, and it was $28.15 / 10^{5}$ for man, $9.31 / 10^{5}$ for woman in China cancer registry which covered 11 cities and counties during 1988$2005^{[39]}$. Two major risk factors identified in Qidong were high prevalence of chronic HBV infection and appreciable dietary aflatoxin exposure, with the HBV infection greatly sensitizing hepatocytes to the mutagenic effects of aflatoxin $^{[50-52]}$. Therefore, the neonatal HB vaccination began in a large controlled clinical trial on 1 September 1983 in Qidong (World Health Organization, Prevention of liver cancer. Technical Report Series 691, World Health Organization, Geneva.1983). It was later registered with Clinical Trials.gov number NCT00222664 ${ }^{[33]}$.

QHBIS is a population-based, cluster randomized, controlled trial of HBV vaccination conducted between 1983-1990 in Qidong. During that time, Qidong had a population of 1.1 million and approximately 13,000 births each year. Approximately 80,000 newborns were randomly assigned into the vaccination or control groups ${ }^{[18,33,53]}$. The study was conducted during a time 
period when HBV vaccine was not available in any rural areas of China. The neonates in the control group did not receive the HBV vaccine at birth, and the neonates in the vaccination group received the three-dose plasma-derived $\mathrm{HB}$ vaccine, which were manufactured and donated by the Merck Company through the WHO. The first dose $(5 \mu \mathrm{g})$ of HBV vaccine was administered within $24 \mathrm{~h}$ after birth, followed by two doses ( $5 \mu \mathrm{g} / \mathrm{dose})$ at 1 and 6 months of age, respectively ${ }^{[18,33]}$. Due to the shortage of hepatitis B immunoglobulin (HBIG), all the newborns were given the vaccine only regardless of their maternal HBsAg status. The protocol can be found via https://doi.org/10.1371/journal.pmed.1001774.s003.

During that time, it was considered ethically justifiable (to have neonates in a control group that did not receive the HBV vaccine) given that the plasma-derived HBV vaccine and recombinant vaccine was not universally available in China. However, in June 2000, the Qidong Center for Disease Control and Prevention (CDC) issued a Notification (File No. 2000-010) regarding HBV catch-up vaccination and booster (https://doi. org/10.1371/journal.pmed.1001774.s004). Children born in 1986-1990 and randomized into the control group of QHBIS received 3 doses of recombinant HBV vaccine at age 10-14 years, and those in the vaccination group received 1 dose of recombinant HBV vaccine at age 10 14 years $^{[33]}$.

This cohort provides us a unique opportunity to examine the efficacy of HBV vaccination administered at different ages against liver cancer and other liver diseases. To reflect the real world situation of HBV vaccination, participants who were involved in the pilot study were no longer included in our analysis ${ }^{[33,54]}$. The 30-year follow-up study demonstrated that more than $72 \%$ efficacy of neonatal vaccination against chronic HBV infection in adulthood was achieved. However, when catch-up HBV vaccination was administered to the control group at age 10-14, the protection efficacy was only $21 \%$ (95\% Cl: $10-30 \%)$, substantially weaker compared to neonatal vaccination, and highlighting the crucial importance of HBV vaccination on neonates against chronic HBV infection in highly HBV endemic regions $^{[33]}$.

Using brain tumor as the negative control, the incidence rates between the vaccination group $\left(0.52 / 10^{5}\right)$ and the control group $\left(0.71 / 10^{5}\right)$ were similar. However, liver cancer cases were only diagnosed in the control group when the participants reached 20 years or older. The incidence rate in the vaccination group was $0.71 / 10^{5}$ person-year, and it was $1.41 / 10^{5}$ person-year in the control group. The protective efficacy was $84 \%$ against HBV-related liver cancer development in young adults $<30$ years. The mortality rate of severe end-stage chronic liver diseases, including liver cancer and chronic liver failure, was significantly lower in the neonatal vaccination group than in the control group $(\mathrm{HR}=0.30$, $95 \% \mathrm{Cl}: 0.11-0.85)$, and the efficacy was $70 \%(95 \% \mathrm{Cl}$ : $15-89 \%)^{[33]}$. The study population was still young and incidence and deaths were very low. Remarkably, in the QHBIS participants, no differences in liver cancer incidence and mortality of chronic liver failure were observed by age 30 years between the individuals who received and those who did not receive the catch-up vaccination $^{[33]}$. These results further addressed the importance of HBV vaccination on neonates in highly $\mathrm{HBV}$ endemic regions.

\section{Risk factors related to vaccination failures in children and HBV vaccination guideline by Chinese Center for Disease Control}

HBV vaccination has been recommended universally for prevention of HBV infection and liver diseases. As of 2012, $183(94 \%)$ of the 193 member states have initiated a HBV vaccination program, with an average of $79 \%$ for the third dose vaccine coverage in infants worldwide (www.who.int/mediacentre/factsheets/fs378/ en). Current data from different areas demonstrated that vaccination is very efficacious in decreasing the HBsAg seroprevalence in children and in preventing the devastating complications of HBV infection in young adults $^{[32,33,55-57]}$.

The vaccination failure in children was found mainly due to being born to $\mathrm{HBeAg}$-positive HBsAg carrier mothers, the mother-to-child transmission (MTCT) ${ }^{[23,58-60]}$. It had been reported that the protective efficacy of HBV vaccination was enhanced by co-administration of HBIG among the neonates who were born to HBsAg-positive mothers. Current recommendations strongly suggest screening pregnant women, and adding on HBIG to the newborns if the mother is positive for HBsAg, regardless of the HBeAg status ${ }^{[23]}$. For neonates born to the HBeAgpositive HBsAg carrier mothers, another important issue affecting the efficacy of HBV vaccination is the timely birth dose of the vaccine. The delay in this initial dose showed an increased risk of infection in children ${ }^{[61]}$. Premature gestation ages or low birth weights also affected the vaccination efficacy ${ }^{[6,63]}$. The administration of a recombinant HBV vaccine shortly after birth is less immunogenic in preterm infants weighing $<1,800 \mathrm{~g}$ at birth than in full term infants. Therefore, it was suggested that the first dose of the vaccine in HBsAgnegative mother's infants weighing $<2,000 \mathrm{~g}$ might be administrated until they reached $2,000 \mathrm{~g}$, or alternatively, until one month old ${ }^{[23]}$.

Based on the practices and experiences conducted in different areas, the National Health and Family Planning Commission of the People's Republic of China issued 
a recommendation/guideline of HBV vaccination in children in December 2016 (http://www.nhfpc.gov.cn/jkj/ s3581/201701/a91fa2f3f9264cc186e1dee4b1f24084. shtml). For general infants, it recommends three doses of HBV vaccines, with the first dose vaccine to be given within $24 \mathrm{~h}$ after delivery. The second and third doses are to be given at 1 month and 6 months of age. Each dose contains $10 \mu \mathrm{g}$ vaccine from recombinant yeast or from Chinese hamster oocyte. For infants born to HBsAgpositive mothers, it recommends the administration of 100 IU HBIG within $12 \mathrm{~h}$ after birth combined with a full course of HBV vaccination. The administration dose is $10 \mu \mathrm{g}$ vaccine from recombinant yeast or $20 \mu \mathrm{g}$ vaccine from Chinese hamster oocyte. The vaccinated infants should be tested for the presence of HBsAg and the anti-HBs titer 1-2 months after completing the third dose of vaccine. If he/she is seronegative for $\mathrm{HBsAg}$ and has anti-HBs $<10 \mathrm{mlU} / \mathrm{mL}$, the fourth dose of HBV vaccine should be given. If the neonates are born to HBsAg-positive mothers at premature gestation ages or low birth weights, the first dose of the vaccine should be administered when they are one month old.

\section{Anti-viral therapy and vaccination for prevention of mother-to-child transmission}

Despite the increased efficacy of passive-active immunization given to infants born to HBsAg-positive mothers, some infants still become infected with $\mathrm{HBV}$, especially those born to $\mathrm{HBeAg}$-positive and highly viremic mothers ${ }^{[59]}$. Many different studies have identified that mothers with significant viremia are at a much higher risk of MTCT. HBV can be vertically transmitted to their infants, indicated by HBV-DNA positivity in the cord blood ${ }^{[64,65]}$. Experience in reducing the risk of perinatal transmission of human immunodeficiency virus with lamivudine-zidovudine combination therapy drove the physicians to follow a similar rationale to prevent the perinatal transmission of HBV-infection. Lamivudine, which strongly inhibits HBV replication, was used to treat eight highly viraemic HBV-positive Caucasian or Negroid pregnant women (HBV-DNA levels $\geq 1.2 \times 10^{9} \mathrm{geq} / \mathrm{mL}$ ) starting from week 34 . The results suggest that reduction of viremia by antiviral therapy may be an effective and safe measure to reduce the risk of MTCT ${ }^{66]}$. Therefore, several studies were conducted to evaluate the risk of MTCT with different maternal levels of HBV DNA. Many studies have identified that serum HBV DNA level in pregnant women was the single most important predictor and independent risk factor for immunoprophylaxis failure in different populations ${ }^{[59,65]}$. Some studies reported that maternal HBV DNA level of $>8 \log 10 \mathrm{IU} / \mathrm{mL}$ was associated with increased likelihood of immunoprophylaxis failure ${ }^{[67,68]}$. A large scale study on more than 1000 Chinese motherinfant pairs found that maternal HBV DNA levels (OR
$=1.88,95 \% \mathrm{Cl}: 1.07-3.30)$ and detectable HBV DNA in the cord blood (OR $=39.67,95 \% \mathrm{Cl}: 14.22-110.64)$ are independent risk factors for immunoprophylaxis failure ${ }^{[65]}$. Maternal HBV-DNA level $>6 \log 10$ copies $/ \mathrm{mL}$ $(200,000 \mathrm{IU} / \mathrm{mL})$ in Chinese women is still associated with the risk of immunoprophylaxis failure ${ }^{[65]}$.

Treatments aimed at lowering HBV-DNA levels during pregnancy may be helpful to ultimately decrease global disease burden. The exact threshold for treatment remains controversial. However most studies have accepted levels greater than $200,000 \mathrm{IU} / \mathrm{mL}$ as significant viremia ${ }^{[69]}$. A Systematic Review and MetaAnalysis found that the use of any antiviral therapy compared to control reduced the MTCT risk as defined by infant HBsAg seropositivity $(\mathrm{RR}=0.3 ; 95 \% \mathrm{Cl}$ : $0.2-$ 0.4 ) or infant HBV-DNA seropositivity $(\mathrm{RR}=0.3 ; 95 \%$ Cl: $0.2-0.5)$ at $6-12$ months. Notably, no significant differences were found in congenital malformation rate, prematurity rate, and Apgar scores ${ }^{[70]}$.

Lamivudine has been used the longest as antiviral therapy of chronic HBV approved by the Chinese Food and Drug Administration, and is currently classified as a pregnancy Category $\mathrm{C}$ drug. A meta-analysis and systematic review of 14 lamivudine studies showed that lamivudine reduced maternal HBV DNA levels, reduced infant HBsAg seropositivity by $11.7 \%$ and reduced infant HBVDNA seropositivity by $21.2 \%$, respectively ${ }^{[70]}$. During the period of January 2009 to March 2011, a prospective, open-label, interventional trial was conducted in Beijing Youan Hospital of China (ClinicalTrials.gov Number: NCT01743079). In the enrolled 700 pregnant women who were $\mathrm{HBsAg}$-positive and $\mathrm{HBeAg}$ positivity, with HBV-DNA levels $>6 \log 10$ copies $/ \mathrm{mL}(200,000 \mathrm{IU} / \mathrm{mL})$, and alanine aminotransferase (ALT) $<40 \mathrm{IU} / \mathrm{mL}, 55$ women were treated with lamivudine, 263 were treated with telbivudine, and the rest (374 women) received no antiviral therapy (the control group). Based on the data from 661 infants who completed the HBV vaccination series and the 52-week follow-up, the study found that mothers who received lamivudine or telbivudine had significantly lower HBV DNA levels than those who received no antiviral therapy. At birth, HBsAg was detected in $20 \%$ of treated and $24 \%$ of untreated newborns; however, by week 52 , an intention-to-treat analysis indicated $2.2 \%(95 \% \mathrm{Cl}: 0.6-3.8)$ of $\mathrm{HBsAg}$ positive infants from the treated versus $7.6 \%(95 \% \mathrm{Cl}$ : 4.9-10.3) in the untreated group $(P=0.001)$, and no difference in $\mathrm{HBsAg}$-positive rate between infants in the lamivudine or telbivudine groups. On-treatment analysis indicated $0 \%$ of $\mathrm{HBsAg}$-positive infants in the treated group versus $2.84 \%$ in the untreated group $(P=0.002)$. The study concluded that lamivudine or telbivudine in late pregnancy for highly viremic mothers was equally effective in reducing MTCT ${ }^{711}$. 
Telbivudine and tenofovir are both classified as pregnancy Category B drugs. A large prospective, controlled trial included $229 \mathrm{HBeAg}$-positive patients with HBV DNA levels $>7 \log 10$ copies $/ \mathrm{mL}$ found that the telbivudine given to 135 pregnant women from weeks 20 to 32 of gestation safely reduce perinatal HBV transmission compared to the 94 untreated pregnant women. MTCT was markedly lower in the treatment group ( $0 \%$ vs. $8 \%$ ) and the immunized infant had a higher proportion of detectable HBsAb (100\% vs. 92\%). A short-term follow-up showed that telbivudine was well-tolerated with no safety concerns in the mothers and/or their infants ${ }^{[72]}$.

Tenofovir Disoproxil Fumarate (TDF) currently remains the first-line therapy for chronic HBV infection based on its safety and resistance profile as well as its potency and efficacy. It is currently rated as pregnancy Category $B$. To evaluate the efficacy and safety of maternal TDF in reducing HBV MTCT, a prospective, multi-center trial was conducted that enrolled $118 \mathrm{HBsAg}$-positive and $\mathrm{HBeAg}$-positive pregnant women with HBV DNA $\geq 7.5 \log 10 \mathrm{IU} / \mathrm{mL}$. In this trial, 56 mothers received no medication and 62 mothers received TDF 300 mg daily from 30-32 weeks of gestation until 1 month postpartum, respectively. Treatment with TDF for highly viremic mothers decreased infant HBV DNA at birth and infant HBsAg positivity at 6 months. However, TDF did not affect the MTCT rate in the per-protocol analysis at the 12-month follow-up ${ }^{[73]}$. To verify the effect and safety of TDF, the China Study Group for the Mother-to-Child Transmission of Hepatitis B included 200 mothers who were positive for $\mathrm{HBeAg}$ and had an HBV DNA level higher than 200,000 IU/mL (ClinicalTrials.gov number NCT01488526) ${ }^{[74]}$. The participants were randomly assigned in a 1:1 ratio to receive usual care without antiviral therapy or to receive TDF from 30 to 32 weeks of gestation until postpartum week 4 . At delivery, $68 \%$ of the mothers in the TDF group (66 of 97 women) had an HBV DNA level $<200,000 \mathrm{IU} / \mathrm{mL}$, while only $2 \%$ of the mothers had an HBV DNA level $<200,000 \mathrm{IU} / \mathrm{mL}$ in the control group. The TDF effect in reducing mothers' HBV DNA level was significant $(P<0.001)$. All the infants received immunoprophylaxis. At postpartum week 28 , the MTCT rate was found to be significantly lower in the TDF group than in the control group, both in the intentionto-treat analysis [with transmission of virus to $5 \%$ of the infants (5 of 97$)$ vs. $18 \%$ (18 of 100), $P=0.007$ ] and the per-protocol analysis [with transmission of virus to $0 \mathrm{vs}$. $7 \%$ (6 of 88), $P=0.01]$. Notably, there was no significant difference in the fetal safety profiles between the two groups ${ }^{[75]}$. The results indicated that it might be too late to prevent the MTCT to commence the TDF treatment at 30 to 32 weeks of gestation if the pregnant women had higher viremic $\mathrm{HBV}^{\left[{ }^{[3]}\right.}$. As the participants were different, antiviral therapy for pregnant women with high $\mathrm{HBV}$ DNA levels is recommended in various guidelines including the AASLD, EASL and APASL. A long term follow-up should be conducted regarding the safety of the mothers and/or their infants. This work was funded by the State Key Projects Specialized on Infection Diseases of the Thirteenth 5-year Plan of China.

\section{Status of immunological memory after neonatal vaccination in young adults}

In children, HBV vaccination proves to be very efficacious in decreasing HBsAg seroprevalence ${ }^{[23,25,27,28,33,58]}$. After 10-15 years of the vaccination, neutralizing antibodies (anti-HBs) waned or reached undetectable levels in many individuals, and some became seropositive with anti-HBV core antigen (anti-HBc) ${ }^{[75,76]}$. Although HBV primary infection in the perinatal period and early life has a high rate of chronicity, the possibility of becoming chronically infected in unprotected young adulthood was reported to be about $2.7-7.7 \%$ after horizontal transmission ${ }^{[12,14,77]}$. It is necessary to confirm the efficacy of neonatal vaccination in protecting young adults who later had low or absent levels of anti-HBs.

In order to understand the long-lasting immunity in preventing chronic HBV infection, Zanetti and colleagues introduced a booster test to assess the presence of anamnestic responses against HBV infection based on the principle that re-exposure of HBsAg in recombinant vaccine should mimic the response to wildtype HBV infection ${ }^{[78]}$. The enrolled population in this study consisted of children born to HBsAg-negative mothers and vaccinated adolescents (Air Force recruits), who were all vaccinated 10 years before the enrollment. Serum anti-HBs levels of each individual was firstly quantified, followed by giving $10 \mu \mathrm{g}$ recombinant HBV vaccine if they were seronegative for anti-HBc. Serum anti-HBs level in each of the participants was quantified again two weeks later. Presence of an anamnestic response was defined as those with prebooster antiHBs titers $<10 \mathrm{mlU} / \mathrm{mL}$ and post-booster titers $\geq 10$ $\mathrm{mlU} / \mathrm{mL}$, a representation of protection conferred through immunologic memory. Later studies that used similar or modified methods, which also determined the presence of HBsAg-specific T cells, were conducted in many different populations worldwide ${ }^{[79]}$. These results revealed that HBV vaccine does elicit immunologic memory, in which memory B cells could appropriately generate a robust anamnestic response to $\mathrm{HBsAg}$ even if the anti-HBs titer falls below $10 \mathrm{mlU} / \mathrm{mL}$.

Nevertheless, the conclusion is controversial regarding the immune protection of the uninfected children/ adolescents who had serum anti-HBs $<10 \mathrm{mlU} / \mathrm{mL}$, based on the studies conducted in the vaccinated population who lived in areas with different HBV 
prevalence and different maternal HBV status ${ }^{[79]}$. Results from the investigations conducted in Taiwan ${ }^{[80,81]}$, in Thailand ${ }^{[82]}$, and in Qidong of China ${ }^{[83]}$ indicated that a notable proportion of fully vaccinated adolescents had no or low immunological memories against HBsAg. All enrolled populations in these studies received infantile $\mathrm{HBV}$ vaccination and lived in high HBV endemic areas. Because the duration and uniformity of this immunologic memory after primary vaccination at infancy is uncertain, these studies would suggest a necessary consideration of 1 or 2 booster doses. However, other studies conducted in Italy ${ }^{[78]}$, that enrolled participants who were all born to HBsAg-negative mothers, and in Hong Kong ${ }^{[84]}$, that enrolled children who received primary HBV vaccination at ages 3 months to 11 years, found significant anamnestic response among the vaccinated populations. Based on the percentage of the anamnestic responders, these investigators suggested that the primary vaccination confers lifelong protection against HBV infection and no booster is needed ${ }^{[78,79,84,85]}$.

HBV breakthrough infection in young adults may occur if the immunologic memory to HBsAg is absent upon sexual, or horizontal exposure including household HBV exposure $^{[86]}$. The setting of booster tests conducted in different studies was different. It is still questionable whether all the adolescents uniformly remain protected against HBV infection when they were engaged in more social activities. The duration and immunologic memory status after primary vaccination might be different when they were born to mothers with different maternal status and the ages of vaccination received. In the last decade, reports of HBV infection among the vaccinated young adults have been documented ${ }^{[87,88]}$. A study conducted in Qidong of China, that enrolled a total of 2,919 young adults aged 19-21 years who received plasma-derived neonatal HBV vaccination found a total of $124(4.2 \%$, 124/2,289) participants were HBsAg negative, but double positive for anti-HBs and anti-HBc [HBsAg(-) \& anti-HBs(+) \& anti-HBc(+)]. None of them were positive for $\mathrm{HBeAg}$ or for anti-HBe or for anti-HCV. Notably, $7 / 124(5.65 \%)$ individuals with seromarkers of $\mathrm{HBsAg}(-)$ \& anti-HBs(+) \& anti-HBc(+) had serum ALT $\geq 40 \mathrm{U} / \mathrm{mL}^{[87]}$. Serum levels of HBV DNA were quantified among the 124 individuals, and $14 / 124(11.3 \%)$ of them had > 10,000 copies $/ \mathrm{mL}, 37 / 124(29.8 \%)$ of them had 500 10,000 copies $/ \mathrm{mL}$, and $73 / 124$ (58.9\%) were below the detection limitation. The longitudinal follow-up studies found that some of the vaccinated children became infected with $\mathrm{HBV}$ in adulthood when they lost anti-HBs at childhood ${ }^{[83,87]}$.

\section{Adolescent booster to children born to HBsAg-positive mothers decreased the risk of HBV infection}

Although investigators worldwide have determined and accumulated evidence regarding the presence of immunologic memory by the booster test ${ }^{[79]}$, HBV breakthrough infection still happened. For precise prevention against chronic HBV infection, it is necessary to understand the human immune responses to HBV vaccine in different individuals with distinct $\mathrm{HBV}$ exposure status in the prenatal period. Recently, it has been demonstrated that the immunological response pattern to microbes/microbial products in the HBVexposed neonates was very different from the healthy ones. Prenatal exposure to HBV induced complex changes in the newborn's immune system ${ }^{[89]}$. Follow-up studies worldwide have demonstrated that children were well protected after HBV vaccination. More evidence is needed regarding the adolescent booster effect against $\mathrm{HBV}$ infection based on different maternal HBsAgcarrying status.

HBsAg has been detected in amniotic fluid, cord blood, breast milk, vaginal fluids, and infant gastric content ${ }^{[64,90]}$. According to the immune selection theory, $\mathrm{T}$ cells that recognize the epitopes in $\mathrm{HBsAg}$ with highaffinity receptors (TCR) might be deleted during immune system development ${ }^{[91]}$. Basic immunology studies have revealed that the differentiation and proliferation of specific antibody producing $B$ cells was regulated by a distinct $T$ cell subset, the follicular helper T cells (Tfh) ${ }^{[92]}$. Although the murine immune system is different from that of humans, we can understand the potential implication from the murine immune responses to model antigen. Experimental data by using the I-Ek-restricted helper T cell response of B10.BR mice to pigeon cytochrome $c$, the tractable protein vaccination model for studying different TCR affinities, demonstrated that significantly more T cells with high affinity TCR developed into "resident" Tfh cells in vivo than the T cells with low affinity TCR, and the low affinity clonotypes of $T$ cells failed to form memory ${ }^{[93,94]}$. The experimental data revealed that Tfh function was regulated by the strength of $T$ cell antigen receptor binding, i.e. TCR affinity. Therefore, the function of Tfh and the $B$ cell memory after primary vaccination in the individuals born to healthy mothers should not be the same as those born to HBsAg-positive mothers and those born to $\mathrm{HBeAg}$ - \& HBsAg-positive mothers. Currently, no data is documented about the difference.

Sexual contact is an important pathway for HBV transmission in low HBV endemic areas ${ }^{[86]}$. Universal neonatal HBV vaccination significantly reduces the HBsAg seroprevalence, and horizontal exposure will be the major route of HBV infection. Because of the controversial conclusion regarding immune protection of the uninfected children/adolescents who had serum anti-HBs $<10 \mathrm{mlU} / \mathrm{mL}$, it is still uncertain whether all the children who were protected by primary vaccination 
are uniformly resistant to chronic HBV infection when they grow up and engage in risky behaviors that might increase HBV exposure.

Studies were done to examine the different responses to booster doses conducted in different areas, to determine if this might be due to enrolling populations with different or unknown maternal HBsAg status. Recently, by enrolling the participants of the vaccination group in the QHBIS, Wang et al. ${ }^{[54]}$ addressed the question of adolescent booster effect against HBV infection in individuals born to mothers with different HBsAg-carrying status ${ }^{[54]}$. In this study, a total of 9,793 vaccinated individuals, who were $\mathrm{HBsAg}(-)$ at childhood (10-11 years of age), re-donated their blood samples for HBV serological surveys in mature adulthood (2328 years of age). Among them, a total of 7,414 children received one dose $(10 \mu \mathrm{g})$ of recombinant HBV vaccine booster and 2,379 did not receive the adolescent booster. Although the booster was not randomized, the distributions between the participants who received the booster and those who did not receive the booster were similar in age, gender, maternal HBsAg status, maternal childbearing age, and family income per capita. Their results showed that HBV breakthrough infection occurred in the vaccinated individuals, who had been protected at childhood by a neonatal vaccination series. Some of the infection developed chronicity in adulthood, especially among the individuals who were born to HBsAg-positive mothers and lost anti-HBs or anti-HBs $<10 \mathrm{mlU} / \mathrm{mL}$ in the childhood. Hence, some of the adolescents born to HBsAg-positive mothers might be susceptible to chronic $\mathrm{HBV}$ infection if serum anti-HBs is $<10 \mathrm{mIU} / \mathrm{mL}^{[95,96]}$.

Further analysis showed that one dose of adolescent booster provided protection (against chronic HBV infection in adulthood) to these high-risk individuals who were born to $\mathrm{HBsAg}$-positive mothers and had lost antiHBs or had anti-HBs $<10 \mathrm{mlU} / \mathrm{mL}$. Nevertheless, no booster effect was observed in those who were born to HBsAg-negative mothers, regardless of their anti-HBs status at 10-11 years of age when they completed the neonatal three-dose HBV vaccine series. The difference in immunity in the HBV-exposed neonates was proven to be very different from the healthy ones ${ }^{[89]}$. When they grow up, their immunity and the immunological memory in the prenatal HBV-exposed individuals seem to be also different in their response against chronic HBV infection. The presence of immunological memory and effect of adolescent booster should be re-visited ${ }^{[95,96]}$. A recent study reported that the HBsAg prevalence was 6.35$6.47 \%$ in men aged $25-39$ years living in the rural areas of China ${ }^{[97]}$, indicating the high risk of HBV infection upon sexual, parenteral, or horizontal (household) HBV exposure. Following the documentation of HBV infection among vaccinated young adults ${ }^{[87,88]}$, it might be appropriate to receive the adolescent boosters, especially for the high-risk individuals ${ }^{[33,56,80,82,88]}$.

\section{Experience and recommendation to reduce liver cancer risk beginning at birth by preventing chronic HBV infection}

To control chronic HBV infection, plasma-derived HBV vaccine, the first generation vaccine, had been administered to millions of infants. In addition, due to various reasons, the HBIG was not administered to high-risk infants who were born to HBsAg-positive mothers in many low- and middle-income countries and areas $^{[23]}$. The plasma-derived HBV vaccine has now been totally replaced by recombinant HBV vaccines, and most of the high-risk infants were immunized together with $\mathrm{HBIG}$ administration.

As the population who was vaccinated with plasmaderived HBV vaccine stepped into their third decades, we can get further insights from them by monitoring their HBV serological markers, and disease development. The studies based on QHBIS provided some information on $\mathrm{HBV}$ vaccination strategies in controlling chronic HBV infection, liver cancer, and chronic liver failure. Our accumulated clinical data on using antiviral therapies in HBV-infected Chinese pregnant women with higher viremia have shown efficacy in blocking MTCT transmission of HBV. All these experiences will be helpful for better controlling PLC, especially HCC, by eradicating HBV beginning at birth.

The experiences and recommendations are as follows [Table 1]: (1) in endemic regions, HBV vaccination in neonates is crucial against chronic HBV infection. Although catch-up vaccination given after age 10 was useful, the protection efficacy was substantially weaker compared to neonatal vaccination; (2) children/ adolescents born to mothers with different HBsAgstatus had distinct immunity against chronic HBV infection, even after initial protection offered by HBV vaccination. The adolescents/young adults seem to be susceptible to chronic HBV infection when they were born to HBsAg-positive mothers when they have lost anti-HBs or when their anti-HBs is $<10 \mathrm{mlU} / \mathrm{mL}$. It is recommended to have at least one booster dose given during adolescence to those who were born to HBsAg-positive mothers and had lost anti-HBs or when their anti-HBs is $<10 \mathrm{mlU} / \mathrm{mL}$, to ensure the immunity against chronic HBV infection; (3) to prevent MTCT transmission of HBV, screening for HBsAg in the first trimester of pregnancy is strongly recommended; (4) For pregnant women with serum HBV DNA levels > $200,000 \mathrm{IU} / \mathrm{mL}$, antiviral treatment is recommended. Therapy with tenofovir or telbivudine should start at 
Table 1: Summary of recommendations for HBV vaccinations

\begin{tabular}{|c|c|}
\hline Setting & Recommendation \\
\hline $\begin{array}{l}\text { Pregnancy } \\
\text { HBsAg-negative }\end{array}$ & $\begin{array}{l}\text { Screening for HBsAg in the first trimester; } \\
\text { Receive three doses of HBV vaccine: the first dose to be given within } 24 \mathrm{~h} \text { after delivery, the } \\
\text { second and third doses to be given at } 1 \text { month and } 6 \text { months of age }\end{array}$ \\
\hline $\begin{array}{l}\text { Pregnancy } \\
\text { HBsAg-positive } \\
\text { HBV DNA }<200,000 \mathrm{IU} / \mathrm{mL}\end{array}$ & $\begin{array}{l}\text { Screening for HBsAg in the first trimester and determine the serum levels of HBV DNA; } \\
\text { Administration of } 100 \mathrm{IU} \mathrm{HBIG} \text { within } 12 \mathrm{~h} \text { after birth in combination with a full course of HBV } \\
\text { vaccination. The administration dose is } 10 \mu \mathrm{g} \text { vaccine from recombinant yeast or } 20 \mu \mathrm{g} \text { vaccine from } \\
\text { Chinese hamster oocyte; } \\
\text { The vaccinated infants should be tested for the presence of HBsAg and the anti-HBs titer } 1-2 \\
\text { month after completing the third dose of vaccine; } \\
\text { The fourth dose of } \mathrm{HB} \text { vaccine should be given if he/she is seronegative for HBsAg and had anti- } \\
\mathrm{HBs}<10 \mathrm{mlU} / \mathrm{mL}\end{array}$ \\
\hline $\begin{array}{l}\text { Pregnancy } \\
\text { HBsAg-positive } \\
\text { HBV DNA > 200,000 IU/mL }\end{array}$ & $\begin{array}{l}\text { Screening for HBsAg in the first trimester and determine the serum levels of HBV DNA. Antiviral } \\
\text { treatment is recommended; } \\
\text { Antiviral therapy using tenofovir or telbivudine should start at week } 24-28 \text { of gestation to reduce the } \\
\text { risk of perinatal transmission of HBV; } \\
\text { For newborns: administration of } 100 \text { IU HBIG within } 12 \mathrm{~h} \text { after birth in combination with a full } \\
\text { course of HBV vaccination. The administration dose is } 10 \mu \mathrm{g} \text { vaccine from recombinant yeast or } 20 \\
\mu \mathrm{g} \text { vaccine from Chinese hamster oocyte; } \\
\text { The vaccinated infants should be tested for the presence of HBsAg and the anti-HBs titer } 1-2 \\
\text { month after completing the third dose of vaccine; } \\
\text { The fourth dose of HB vaccine should be given if he/she is seronegative for HBsAg and had anti- } \\
\mathrm{HBs}<10 \mathrm{mIU} / \mathrm{mL} \\
\text { For mothers, the antiviral therapy could be discontinued at birth to } 1 \text { month postpartum. With } \\
\text { discontinuation of treatment, women should be monitored for ALT flares every } 3 \text { months for } 6 \\
\text { months }\end{array}$ \\
\hline $\begin{array}{l}\text { Vaccinated adolescents completed } \\
\text { neonatal HBV vaccination series } \\
\text { without HBIG administration }\end{array}$ & $\begin{array}{l}\text { If born to HBsAg-positive mother, determine the } \mathrm{HBsAg} \text { and anti-HBs levels. Receive the HBV } \\
\text { vaccine booster to generate anti-HBs }>10 \mathrm{mIU} / \mathrm{mL} \text {; } \\
\text { If born to HBsAg-negative mother, no HBV vaccine booster necessary in general setting }\end{array}$ \\
\hline
\end{tabular}

HBsAg: hepatitis B surface antigen; HBV: hepatitis B virus; HBIG: hepatitis B immunoglobulin

week 24-28 of gestation to reduce the risk of perinatal transmission of HBV. The oral antiviral drugs currently are pregnancy Class $C$ (lamivudine, entecavir, and adefovir dipivoxil) or Class B (telbivudine and tenofovir). Telbivudine or tenofovir is recommended based on the studies conducted in multiple medical centers and the recommendations from AASLD, EASL and APASL; (5) for the mothers, antiviral therapy could be discontinued at delivery to 1 month postpartum. With discontinuation of treatment, women should be monitored for ALT flares every 3 months for 6 months; (6) for infants born to HBsAg-positive mothers regardless of the serum HBV DNA levels, the administration of 100 IU HBIG within $12 \mathrm{~h}$ after birth should be combined with a full course of HBV vaccination. The administration dose is $10 \mu \mathrm{g}$ vaccine from recombinant yeast or $20 \mu \mathrm{g}$ vaccine from Chinese hamster oocyte. The vaccinated infants should be tested for the presence of HBsAg and the antiHBs titer 1-2 months after completing the third dose of vaccine. If he/she is seronegative for $\mathrm{HBsAg}$ and has anti-HBs $<10 \mathrm{mlU} / \mathrm{mL}$, the fourth dose of HBV vaccine should be given.

\section{DECLARATIONS}

\section{Acknowledgments}

We thank Dr. Mei-Sze Chua from Stanford University for language polish of this manuscript.

\section{Authors' contributions}

Drafted the outline of this review: C. Qu

Drafted the parts regarding on the hepatitis $B$ immunization: C. Qu, K. Chen

Drafted the parts regarding on the antiviral therapy to pregnant women and prevention of mother to child transmission: Z. Duan, H. Zou

Finalized the manuscript: C. Qu

\section{Financial support and sponsorship}

The study is supported by: State Key Projects Specialized on Infectious Diseases, No. 2017ZX10201201-006003, to CQ; Key research projects for precision medicine, No. 2017YFC0908103, to CQ; State Key Projects Specialized on Infectious Diseases, No. 2017ZX10201201, to ZD; and Beijing Municipal Science \& Technology Commission, No. Z151100003915096 and No. Z16110000516084, to HZ.

\section{Conflicts of interest}

The sponsors of the study had no role in study design, data collection, data analysis, data interpretation, or writing of the manuscript.The findings and conclusion in this review do not represent the official position of Chinese Center of Disease Control and Prevention. The official document can be found via the link of http:// www.nhfpc.gov.cn/jkj/s3581/201701/a91fa2f3f9264cc1 86e1dee4b1f24084.shtml. 


\section{Patient consent \\ Not applicable.}

\section{Ethics approval \\ Not applicable.}

\section{REFERENCES}

1 Zhang Y, Ren JS, Shi JF, Li N, Wang YT, Qu C, Zhang Y, Dai M. International trends in primary liver cancer incidence from 1973 to 2007. BMC Cancer 2015;15:94.

2. Poon D, Anderson BO, Chen LT, Tanaka K, Lau WY, Van Cutsem E, Singh H, Chow WC, Ooi LL, Chow P, Khin MW, Koo WH; Asian Oncology Summit. Management of hepatocellular carcinoma in Asia: consensus statement from the Asian Oncology Summit 2009. Lancet Oncol 2009;10:1111-8.

3. de Martel C, Maucort-Boulch D, Plummer M, Franceschi S. Worldwide relative contribution of hepatitis $\mathrm{B}$ and $\mathrm{C}$ viruses in hepatocellular carcinoma. Hepatology 2015;62:1190-200.

4. Ralphs S, Khan SA. The role of the hepatitis viruses in cholangiocarcinoma. $J$ Viral Hepat 2013;20:297-305.

5. Makvandi M. Update on occult hepatitis B virus infection. World $J$ Gastroenterol 2016;22:8720-34

6. Raimondo G, Pollicino T, Romanò L, Zanetti AR. A 2010 update on occult hepatitis B infection. Pathol Biol (Paris) 2010;58:254-7.

7. Chen $\mathrm{CH}$, Changchien CS, Lee CM, Tung WC, Hung $\mathrm{CH}$, Hu TH, Wang JH, Wang JC, Lu SN. A study on sequence variations in pre-S/ surface, $\mathrm{X}$ and enhancer II/core promoter/precore regions of occult hepatitis B virus in non-B, non-C hepatocellular carcinoma patients in Taiwan. Int J Cancer 2009;125:621-9.

8. Wang M, Wang Y, Feng X, Wang R, Wang Y, Zeng H, Qi J, Zhao H, Li N, Cai J, Qu C. Contribution of hepatitis B, C virus to liver cancer in China North areas: experience from Chinese National Cancer Center. Int J Infect Dis 2017;65:15-21.

9. Yin J, Zhang H, He Y, Xie J, Liu S, Chang W, Tan X, Gu C, Lu W, Wang H, Bi S, Cui F, Liang X, Schaefer S, Cao G. Distribution and hepatocellular carcinoma-related viral properties of hepatitis B virus genotypes in Mainland China: a community-based study. Cancer Epidemiol Biomarkers Prev 2010;19:777-86.

10. Cui Y, Jia J. Update on epidemiology of hepatitis B and C in China. $J$ Gastroenterol Hepatol 2013;28 Suppl 1:7-10.

11. Beath SV, Boxall EH, Watson RM, Tarlow MJ, Kelly DA. Fulminant hepatitis B in infants born to anti-HBe hepatitis B carrier mothers. BMJ 1992;304:1169-70.

12. Chang MH. Hepatitis B virus infection. Semin Fetal Neonatal Med 2007; 12:160-7.

13. Edmunds WJ, Medley GF, Nokes DJ, Hall AJ, Whittle HC. The influence of age on the development of the hepatitis B carrier state. Proc Biol Sci 1993;253:197-201.

14. Hyams KC. Risks of chronicity following acute hepatitis B virus infection: a review. Clin Infect Dis 1995;20:992-1000.

15. Xia GL, Liu CB, Cao HL, Bi SL, Zhan MY, Su CA, Nan JH, Qi $\mathrm{XQ}$. Prevalence of hepatitis $\mathrm{B}$ and $\mathrm{C}$ virus infections in the general Chinese population: results from a nationwide cross-sectional seroepidemiologic study of hepatitis A, B,C, D and E virus infections in China, 1992. Int Hepatol Commun 1996;5:12.

16. Hajarizadeh B, Grebely J, Dore GJ. Epidemiology and natural history of HCV infection. Nat Rev Gastroenterol Hepatol 2013;10:553-62.

17. Beasley RP, Hwang LY, Lin CC, Chien CS. Hepatocellular carcinoma and hepatitis B virus. A prospective study of 22707 men in Taiwan. Lancet 1981;2:1129-33

18. Sun Z, Ming L, Zhu X, Lu J. Prevention and control of hepatitis B in
China. J Med Virol 2002;67:447-50

19. Liang X, Cui F, Hadler S, Wang X, Luo H, Chen Y, Kane M, Shapiro C, Yang W, Wang Y. Origins, design and implementation of the China GAVI project. Vaccine 2013;31 Suppl 9:J8-14.

20. Szmuness W, Stevens CE, Harley EJ, Zang EA, Oleszko WR, William DC, Sadovsky R, Morrison JM, Kellner A. Hepatitis B vaccine: demonstration of efficacy in a controlled clinical trial in a high-risk population in the United States. N Engl J Med 1980;303:833-41.

21. Maupas P, Chiron JP, Barin F, Coursaget P, Goudeau A, Perrin J, Denis F, Mar ID. Efficacy of hepatitis B vaccine in prevention of early HBsAg carrier state in children. Controlled trial in an endemic area (Senegal). Lancet 1981;1:289-92.

22. Szmuness W, Stevens CE, Zang EA, Harley EJ, Kellner A. A controlled clinical trial of the efficacy of the hepatitis B vaccine (Heptavax B): a final report. Hepatology 1981;1:377-85.

23. Chen DS. Hepatitis B vaccination: the key towards elimination and eradication of hepatitis B. J Hepatol 2009;50:805-16.

24. W.H.O. Scientific Group. Prevention of primary liver cancer. Report on a meeting of a W.H.O. Scientific Group. Lancet 1983;1:463-5.

25. Zanetti AR, Van Damme P, Shouval D. The global impact of vaccination against hepatitis B: a historical overview. Vaccine 2008:26:6266-73

26. Zhu X, Zhang XL, Wang L. National EPI vaccination and hepatitis B vaccine coverage rate and the related factors: results from the 1999 nationwide survey. Chin J Vac Immunization 2000;6:193-7. (in Chinese)

27. Liang X, Bi S, Yang W, Wang L, Cui G, Cui F, Zhang Y, Liu J, Gong X, Chen Y, Wang F, Zheng H, Wang F, Guo J, Jia Z, Ma J, Wang H, Luo H, Li L, Jin S, Hadler SC, Wang Y. Epidemiological serosurvey of hepatitis B in China--declining HBV prevalence due to hepatitis B vaccination. Vaccine 2009;27:6550-7.

28. Wang FZ, Zhang GM, Shen LP, Zheng H, Wang F, Miao N, Yuan QL, Sun XJ, Bi SL, Liang XF, Wang HQ. Comparative analyze on hepatitis B seroepidemiological surveys among population aged 1-29 years in different epidemic regions of China in 1992 and 2014 Zhonghua Yu Fang Yi Xue Za Zhi 2017;51:462-8. (in Chinese)

29. Finelli L, Bell BP. Chapter 4: Hepatitis B. Avaliable from: https:// www.cdc.gov/vaccines/pubs/surv-manual/chpt04-hepb.pdf. [Last accessed on 19 Oct 2017]

30. Chang MH, Lee CY, Chen DS, Hsu HC, Lai MY. Fulminant hepatitis in children in Taiwan: the important role of hepatitis B virus. J Pediatr 1987;111:34-9.

31. Huang LM, Chang MH, Hong JY, Lee CY, Chen DS. Changing aetiologic patterns of acute viral hepatitis in Taiwanese children. $J$ Gastroenterol Hepatol 1989;4:339-44.

32. Chiang CJ, Yang YW, You SL, Lai MS, Chen CJ. Thirty-year outcomes of the national hepatitis $\mathrm{B}$ immunization program in Taiwan. JAMA 2013;310:974-6.

33. Qu C, Chen T, Fan C, Zhan Q, Wang Y, Lu J, Lu LL, Ni Z, Huang F, Yao H, Zhu J, Fan J, Zhu Y, Wu Z, Liu G, Gao W, Zang M, Wang D, Dai M, Hsia CC, Zhang Y, Sun Z. Efficacy of neonatal HBV vaccination on liver cancer and other liver diseases over 30year follow-up of the Qidong hepatitis B intervention study: a cluster randomized controlled trial. PLoS Med 2014;11:e1001774.

34. Chen HL, Chang CJ, Kong MS, Huang FC, Lee HC, Lin CC, Liu CC, Lee IH, Wu TC, Wu SF, Ni YH, Hsu HY, Chen DS, Chang MH. Pediatric fulminant hepatic failure in endemic areas of hepatitis B infection: 15 years after universal hepatitis B vaccination. Hepatology 2004;39:58-63.

35. Chang MH, You SL, Chen CJ, Liu CJ, Lee CM, Lin SM, Chu HC, Wu TC, Yang SS, Kuo HS, Chen DS; Taiwan Hepatoma Study Group. Decreased incidence of hepatocellular carcinoma in hepatitis B vaccinees: a 20 -year follow-up study. $J$ Natl Cancer Inst 2009;101:1348-55.

36. McMahon BJ, Bulkow LR, Singleton RJ, Williams J, Snowball M, 
Homan C, Parkinson AJ. Elimination of hepatocellular carcinoma and acute hepatitis B in children 25 years after a hepatitis B newborn and catch-up immunization program. Hepatology 2011;54:801-7.

37. Gwack J, Park SK, Lee EH, Park B, Choi Y, Yoo KY. Hepatitis B vaccination and liver cancer mortality reduction in Korean children and adolescents. Asian Pac J Cancer Prev 2011;12:2205-8.

38. Tajiri H, Tanaka H, Brooks S, Takano T. Reduction of hepatocellular carcinoma in childhood after introduction of selective vaccination against hepatitis B virus for infants born to HBV carrier mothers. Cancer Causes Control 2011;22:523-7.

39. Gao J, Xie L, Chen WQ, Zhang SW, Wu QJ, Yang Y, Yang WS, Tan YT, Xiang YB. Rural-urban, sex variations, and time trend of primary liver cancer incidence in China, 1988-2005. Eur J Cancer Prev 2013;22:448-54.

40. Zuo T, Zheng R, Zeng H, Zhang S, Chen W. Analysis of liver cancer incidence and trend in China. Zhonghua Zhong Liu Za Zhi 2015;37:691-6. (in Chinese)

41. Kurahashi N, Inoue M, Iwasaki M, Tanaka Y, Mizokami M, Tsugane S; JPHC Study Group. Vegetable, fruit and antioxidant nutrient consumption and subsequent risk of hepatocellular carcinoma: a prospective cohort study in Japan. Br J Cancer 2009;100:181-4.

42. Zhang W, Shu XO, Li H, Yang G, Cai H, Ji BT, Gao J, Gao YT, Zheng W, Xiang YB. Vitamin intake and liver cancer risk: a report from two cohort studies in China. J Natl Cancer Inst 2012;104:1173-81.

43. Liu Y, Chang CC, Marsh GM, Wu F. Population attributable risk of aflatoxin-related liver cancer: systematic review and meta-analysis. Eur J Cancer 2012;48:2125-36

44. Sun Z, Chen T, Thorgeirsson SS, Zhan Q, Chen J, Park JH, Lu P, Hsia CC, Wang N, Xu L, Lu L, Huang F, Zhu Y, Lu J, Ni Z, Zhang Q, Wu Y, Liu G, Wu Z, Qu C, Gail MH. Dramatic reduction of liver cancer incidence in young adults: 28 year follow-up of etiological interventions in an endemic area of China. Carcinogenesis 2013;34:1800-5

45. Zhang W, Xiang YB, Li HL, Yang G, Cai H, Ji BT, Gao YT, Zheng W, Shu XO. Vegetable-based dietary pattern and liver cancer risk: results from the Shanghai women's and men's health studies. Cancer Sci 2013;104:1353-61.

46. Chen JG, Kensler TW. Changing rates for liver and lung cancers in Qidong, China. Chem Res Toxicol 2014;27:3-6.

47. Pol S. Hepatitis: HBV vaccine--the first vaccine to prevent cancer. Nat Rev Gastroenterol Hepatol 2015;12:190-1.

48. Karnik R, Singal AG. To "B" or not to "B": efficacy of a neonatal hepatitis B vaccination program to prevent primary liver cancer and end-stage liver disease. Gastroenterology 2015;148:1073-5.

49. Chen JG, Zhu J, Parkin DM, Zhang YH, Lu JH, Zhu YR, Chen TY. Trends in the incidence of cancer in Qidong, China, 1978-2002. Int J Cancer 2006;119:1447-54.

50. Xia QJ. Liver cell cancer in the young and adolescent and its relation to hepatitis B virus (HBV). Zhonghua Zhong Liu Za Zhi 1984;6:4136. (in Chinese)

51. Sun Z, Lu P, Gail MH, Pee D, Zhang Q, Ming L, Wang J, Wu Y, Liu $\mathrm{G}$, Wu Y, Zhu Y. Increased risk of hepatocellular carcinoma in male hepatitis B surface antigen carriers with chronic hepatitis who have detectable urinary aflatoxin metabolite M1. Hepatology 1999;30:37983.

52. Ming L, Thorgeirsson SS, Gail MH, Lu P, Harris CC, Wang N, Shao Y, Wu Z, Liu G, Wang X, Sun Z. Dominant role of hepatitis B virus and cofactor role of aflatoxin in hepatocarcinogenesis in Qidong, China. Hepatology 2002;36:1214-20.

53. Sun Z, Zhu Y, Stjernsward J, Hilleman M, Collins R, Zhen Y, Hsia CC, Lu J, Huang F, Ni Z. Design and compliance of HBV vaccination trial on newborns to prevent hepatocellular carcinoma and 5-year results of its pilot study. Cancer Detect Prev 1991;15:313-8.
54. Wang Y, Chen T, Lu LL, Wang M, Wang D, Yao H, Fan C, Qi J, Zhang Y, Qu C. Adolescent booster with hepatitis B virus vaccines decreases HBV infection in high-risk adults. Vaccine 2017;35:106470.

55. Romano' L, Paladini S, Van Damme P, Zanetti AR. The worldwide impact of vaccination on the control and protection of viral hepatitis B. Dig Liver Dis 2011;43 Suppl 1:S2-7.

56. Trépo C, Chan HL, Lok A. Hepatitis B virus infection. Lancet 2014;384:2053-63.

57. Locarnini S, Hatzakis A, Chen DS, Lok A. Strategies to control hepatitis B: Public policy, epidemiology, vaccine and drugs. J Hepatol 2015;62:S76-86.

58. Ni YH, Huang LM, Chang MH, Yen CJ, Lu CY, You SL, Kao JH, Lin YC, Chen HL, Hsu HY, Chen DS. Two decades of universal hepatitis $B$ vaccination in taiwan: impact and implication for future strategies. Gastroenterology 2007;132:1287-93.

59. Pan CQ, Duan ZP, Bhamidimarri KR, Zou HB, Liang XF, Li J, Tong MJ. An algorithm for risk assessment and intervention of mother to child transmission of hepatitis B virus. Clin Gastroenterol Hepatol 2012;10:452-9.

60. Guidelines for the prevention, care and treatment of persons with chronic hepatitis B infection. Avaliable from: http://apps.who.int/iris/ bitstream/10665/154590/1/9789241549059 eng.pdf. [Last accessed on 19 Oct 2017]

61. Ekra D, Herbinger KH, Konate S, Leblond A, Fretz C, Cilote V, Doua C, Da Silva A, Gessner BD, Chauvin P. A non-randomized vaccine effectiveness trial of accelerated infant hepatitis B immunization schedules with a first dose at birth or age 6 weeks in Côte d'Ivoire. Vaccine 2008;26:2753-61.

62. Lau YL, Tam AY, Ng KW, Tsoi NS, Lam B, Lam P, Yeung CY. Response of preterm infants to hepatitis B vaccine. J Pediatr 1992;121:962-5

63. Freitas da Motta MS, Mussi-Pinhata MM, Jorge SM, Tachibana Yoshida CF, Sandoval de Souza CB. Immunogenicity of hepatitis B vaccine in preterm and full term infants vaccinated within the first week of life. Vaccine 2002;20:1557-62.

64. Lu LL, Chen BX, Wang J, Wang D, Ji Y, Yi HG, Chen T, Zhang Y, Petersen E, Li Q, Qu C. Maternal transmission risk and antibody levels against hepatitis B virus e antigen in pregnant women. Int $J$ Infect Dis 2014;28:41-4.

65. Zou H, Chen Y, Duan Z, Zhang H, Pan C. Virologic factors associated with failure to passive-active immunoprophylaxis in infants born to HBsAg-positive mothers. J Viral Hepat 2012;19:e18-25.

66. van Zonneveld M, van Nunen AB, Niesters HG, de Man RA, Schalm SW, Janssen HL. Lamivudine treatment during pregnancy to prevent perinatal transmission of hepatitis B virus infection. J Viral Hepat 2003;10:294-7.

67. Wiseman E, Fraser MA, Holden S, Glass A, Kidson BL, Heron LG, Maley MW, Ayres A, Locarnini SA, Levy MT. Perinatal transmission of hepatitis B virus: an Australian experience. Med $J$ Aust 2009;190:489-92.

68. Singh AE, Plitt SS, Osiowy C, Surynicz K, Kouadjo E, Preiksaitis J, Lee B. Factors associated with vaccine failure and vertical transmission of hepatitis B among a cohort of Canadian mothers and infants. J Viral Hepat 2011;18:468-73.

69. Jaffe A, Brown RS Jr. A review of antiviral use for the treatment of chronic hepatitis B virus infection in pregnant women. Gastroenterol Hepatol (N Y) 2017;13:154-63.

70. Brown RS Jr, McMahon BJ, Lok AS, Wong JB, Ahmed AT, Mouchl MA, Wang Z, Prokop LJ, Murad MH, Mohammed K. Antiviral therapy in chronic hepatitis B viral infection during pregnancy: a systematic review and meta-analysis. Hepatology 2016;63:319-33.

71. Zhang H, Pan CQ, Pang Q, Tian R, Yan M, Liu X. Telbivudine or 
lamivudine use in late pregnancy safely reduces perinatal transmission of hepatitis B virus in real-life practice. Hepatology 2014;60:468-76.

72. Han GR, Cao MK, Zhao W, Jiang HX, Wang CM, Bai SF, Yue X, Wang GJ, Tang X, Fang ZX. A prospective and open-label study for the efficacy and safety of telbivudine in pregnancy for the prevention of perinatal transmission of hepatitis B virus infection. $J$ Hepatol 2011;55:1215-21.

73. Chen HL, Lee CN, Chang CH, Ni YH, Shyu MK, Chen SM, Hu JJ, Lin HH, Zhao LL, Mu SC, Lai MW, Lee CL, Lin HM, Tsai MS, Hsu JJ, Chen DS, Chan KA, Chang MH; Taiwan Study Group for the Prevention of Mother-to-Infant Transmission of HBV (PreMIT Study); Taiwan Study Group for the Prevention of Mother-to-Infant Transmission of HBV PreMIT Study. Efficacy of maternal tenofovir disoproxil fumarate in interrupting mother-to-infant transmission of hepatitis B virus. Hepatology 2015;62:375-86.

74. Pan CQ, Duan Z, Dai E, Zhang S, Han G, Wang Y, Zhang H, Zou H, Zhu B, Zhao W, Jiang H; China Study Group for the Mother-toChild Transmission of Hepatitis B. Tenofovir to prevent hepatitis B transmission in mothers with high viral load. $N$ Engl $J$ Med 2016;374:2324-34.

75. Wainwright RB, Bulkow LR, Parkinson AJ, Zanis C, McMahon BJ. Protection provided by hepatitis B vaccine in a Yupik Eskimo population--results of a 10-year study. J Infect Dis 1997;175:674-7.

76. Dentinger CM, McMahon BJ, Butler JC, Dunaway CE, Zanis CL, Bulkow LR, Bruden DL, Nainan OV, Khristova ML, Hennessy TW, Parkinson AJ. Persistence of antibody to hepatitis B and protection from disease among Alaska natives immunized at birth. Pediatr Infect Dis $J$ 2005;24:786-92.

77. Beasley RP, Hwang LY, Lin CC, Ko YC, Twu SJ. Incidence of hepatitis among students at a university in Taiwan. Am J Epidemiol 1983;117:213-22.

78. Zanetti AR, Mariano A, Romanò L, D'Amelio R, Chironna M, Coppola RC, Cuccia M, Mangione R, Marrone F, Negrone FS, Parlato A, Zamparo E, Zotti C, Stroffolini T, Mele A; Study Group. Long-term immunogenicity of hepatitis B vaccination and policy for booster: an Italian multicentre study. Lancet 2005;366:1379-84.

79. FitzSimons D, Hendrickx G, Vorsters A, Van Damme P. Hepatitis B vaccination: a completed schedule enough to control HBV lifelong? Milan, Italy, 17-18 November 2011. Vaccine 2013;31:584-90.

80. Lu CY, Ni YH, Chiang BL, Chen PJ, Chang MH, Chang LY, Su IJ, Kuo HS, Huang LM, Chen DS, Lee CY. Humoral and cellular immune responses to a hepatitis B vaccine booster 15-18 years after neonatal immunization. J Infect Dis 2008;197:1419-26.

81. Jan CF, Huang KC, Chien YC, Greydanus DE, Davies HD, Chiu TY, Huang LM, Chen CJ, Chen DS. Determination of immune memory to hepatitis B vaccination through early booster response in college students. Hepatology 2010;51:1547-54.

82. Chinchai T, Chirathaworn C, Praianantathavorn K, Theamboonlers A, Hutagalung Y, Bock PH, Thantiworasit P, Poovorawan Y. Long-term humoral and cellular immune response to hepatitis B vaccine in highrisk children 18-20 years after neonatal immunization. Viral Immunol 2009;22:125-30

83. Zhu CL, Liu P, Chen T, Ni Z, Lu LL, Huang F, Lu J, Sun Z, Qu C. Presence of immune memory and immunity to hepatitis $\mathrm{B}$ virus in adults after neonatal hepatitis B vaccination. Vaccine 2011;29:7835-41.

84. But DY, Lai CL, Lim WL, Fung J, Wong DK, Yuen MF. Twentytwo years follow-up of a prospective randomized trial of hepatitis $\mathrm{B}$ vaccines without booster dose in children: final report. Vaccine 2008;26:6587-91

85. McMahon BJ, Dentinger CM, Bruden D, Zanis C, Peters H, Hurlburt D, Bulkow L, Fiore AE, Bell BP, Hennessy TW. Antibody levels and protection after hepatitis B vaccine: results of a 22-year follow-up study and response to a booster dose. J Infect Dis 2009;200:1390-6.

86. Neaigus A, Gyarmathy VA, Zhao M, Miller M, Friedman SR, Des Jarlais DC. Sexual and other noninjection risks for HBV and HCV seroconversions among noninjecting heroin users. $J$ Infect Dis 2007;195:1052-61.

87. Xu L, Wei Y, Chen T, Lu J, Zhu CL, Ni Z, Huang F, Du J, Sun Z, Qu C. Occult HBV infection in anti-HBs-positive young adults after neonatal HB vaccination. Vaccine 2010;28:5986-92.

88. Wu TW, Lin HH, Wang LY. Chronic hepatitis B infection in adolescents who received primary infantile vaccination. Hepatology 2013;57:37-45.

89. Hong M, Sandalova E, Low D, Gehring AJ, Fieni S, Amadei B, Urbani S, Chong YS, Guccione E, Bertoletti A. Trained immunity in newborn infants of HBV-infected mothers. Nat Commun 2015;6:6588.

90. Lee AK, Ip HM, Wong VC. Mechanisms of maternal-fetal transmission of hepatitis B virus. J Infect Dis 1978;138:668-71.

91. Starr TK, Jameson SC, Hogquist KA. Positive and negative selection of T cells. Annu Rev Immunol 2003;21:139-76.

92. Crotty S. A brief history of T cell help to B cells. Nat Rev Immunol 2015;15:185-9.

93. Fazilleau N, McHeyzer-Williams LJ, Rosen H, McHeyzer-Williams MG. The function of follicular helper $\mathrm{T}$ cells is regulated by the strength of T cell antigen receptor binding. Nat Immunol 2009; 10:37584.

94. Nurieva RI, Chung Y, Martinez GJ, Yang XO, Tanaka S, Matskevitch TD, Wang YH, Dong C. Bcl6 mediates the development of T follicular helper cells. Science 2009;325:1001-5.

95. Romanò L, Carsetti R, Tozzi AE, Mele A, Zanetti AR. Chronic hepatitis B infection in adolescents vaccinated at birth: an alarm bell in favor of the need for a booster? Hepatology 2014;59:349.

96. Carmody E. Time to re-evaluate the effect of the adolescent booster of hepatitis B vaccine. Int J Infect Dis 2017;60:88-90.

97. Liu J, Zhang S, Wang Q, Shen H, Zhang M, Zhang Y, Yan D, Liu M Seroepidemiology of hepatitis B virus infection in 2 million men aged 21-49 years in rural China: a population-based, cross-sectional study. Lancet Infect Dis 2016;16:80-6. 